\title{
Synthesis of Chain Transfer Agents for RAFT Polymerization by using DBU
}

\author{
Sudershan R. Gondi * \\ Department of Chemistry, Southern Methodist University, 3215 Daniel Avenue, Dallas, Texas \\ 75275-0314, USA
}

\begin{abstract}
Trithiocarbonate TTC, Dithioester DT containing RAFT chain transfer acid agents are efficiently and conveniently esterified by DBU. The significance of the reaction is mild reaction condition, high yield, easy simple workup, and reduction of reaction time. This protocol providing a useful alternative method for ester synthesis and makes the process very viable or more economic.
\end{abstract}

Key words: Trithiocarbonate, Dithioester, RAFT polymerization, DBU, Esterification,

Introduction: Highly ordered material can be obtained by better control over the polymer backbone. To achieve this, a variety of synthetic approaches were explored, controlled free radical polymerization is most important in polymer chemistry, living polymerization techniques afford control over molecular weight, molecular weight distribution, architecture, and functionalities of the resulting polymer. Three commonly used controlled free radical polymerizations 1. Nitroxide-mediated polymerization ${ }^{1}$ (NMP), 2. Atom transfer radical polymerization $^{2}$ (ATRP), and 3. Reversible addition fragmentation techniques ${ }^{3-7}$ (RAFT). RAFT polymerization has received increasing attention in recent years, because it works with the greatest range of vinyl monomers and under a wide variety of experimental conditions. Little 
work has been done for the synthesis of novel trithiocarbonate and dithioester for RAFT polymerization. In general, esters are common intermediates in natural product chemistry due to their stability and accessibility for easy interconversion ${ }^{8}$. The traditional methods ${ }^{9}$ to get the ester is by treating the acid chloride and primary alcohol in presence of base, triethylamine or by coupling of acid with alcohol in presence of imides (DCC or EDC). Though most of these methods require heating or longer reaction time and tedious workup and, in some case, the dithiocarbonate and dithioester functionalities in oxalyl chloride or thionyl chloride are very susceptible, in view of the synthetic importance of esters in particular having trithiocarbonate and dithio ester. It is desirable to have a general and convenient methodology for their synthesis especially, from readily available materials, such as acids, halides and mesylate.

Recently, using organic bases in reaction have gained wide popularity in organic synthesis becomes of its simple work of catalyzing nature and more important selectivity. Among the organic bases, 1,8-Diazabicyclo[5.4.0]undec-7-ene (DBU) as a non-nucleophilic, sterically hindered, tertiary amine base has been widely demonstrated. ${ }^{10}$ In particular; it has been widely used for carrying out a wide range of reactions. ${ }^{11}$ The Baylis-Hillman reaction, ${ }^{12}$ Nef reaction, ${ }^{13}$ Mizuno et al. developed a new chemical fixation of carbon dioxide in the presence of DBU to form substituted $1 H$-quinazoline-2,4-diones, ${ }^{14,15}$ methylation $^{16}$ and benzylation ${ }^{17}$ of $\mathrm{N}$-, O- and S-atoms with nontoxic dimethylcarbonate (DMC) and dibenzylcarbonate (DBC), respectively. These also showed the superiority of DBU over the commonly used acylation catalyst 4(dimethylamino) pyridine in the esterfication of benzoic acid with DMC. ${ }^{18}$ 


\section{Scheme-1}<smiles>[R]COC([R])=O</smiles><smiles>[R7]CCC(C)(C)SC(=S)SC(=S)S[13CH2][Z11]([H])([H])SC([R1])(C)SC(=S)SC([R7])(C)C</smiles>

$\mathrm{R}_{2}=\mathrm{Br}, \mathrm{I}, \mathrm{OMs} . \mathrm{R}_{3}=\mathrm{C}_{2} \mathrm{H}, \mathrm{CH}_{2}-\mathrm{CH}_{2}-\mathrm{N}_{3},-\mathrm{C}_{6} \mathrm{H}_{4}-\mathrm{B}(\mathrm{OH})_{2}$

This observation prompted us to explore the reactivity of $\mathrm{DBU}^{19}$ in organic synthesis for esterfication. In continuation of our work of synthesis of Chain Transfer Agents for RAFT polymerization, herein we wish to report a new method for the synthesis of ester containing the trithiocarbonate and dithio ester using acid and alkyl bromide, iodide and mesiylate in presence of DBU in DMSO at ambient temperature.

Table 2. Reactions of Acids 1a-c with Meisylate, Halides 2a-f with DBU in DMSO solvent:

\begin{tabular}{|l|l|l|c|c|c|}
\hline Entry & substrate & Halide/Mesiylate & $\begin{array}{l}\text { Temp }\left({ }^{\circ} \mathrm{C}\right) / \text { Time } \\
(\mathbf{h})\end{array}$ & Product & $\begin{array}{l}\text { Yield } \\
\text { (\%) }\end{array}$ \\
\hline 1 & Diacid (1a) & PropargylBr, (2a) & 70,6 & $3 \mathrm{a}$ & 94 \\
\hline 2 & $1 \mathrm{a}$ & Propargyl-OMs(2b)22 & 70,6 & $3 \mathrm{a}$ & 79 \\
\hline 3 & $1 \mathrm{a}$ & 1-azido-3-OMs-propane (2c) & 70,6 & $3 \mathrm{c}$ & 15 \\
\hline 4 & $1 \mathrm{a}$ & 1-azido3-iodo-propane (2d) & 70,5 & $3 \mathrm{c}$ & 19 \\
\hline 5 & $1 \mathrm{a}$ & 3 bromomethyl-PhenylBA (2e) & 70,6 & $3 \mathrm{e}$ & 82 \\
\hline 6 & $\mathrm{C}_{12}$ acid, (1b) & $2 \mathrm{a}$ & 70,6 & $4 \mathrm{a}$ & 89 \\
\hline 7 & $1 \mathrm{~b}$ & $2 \mathrm{c}$ & 70,5 & $4 \mathrm{c}$ & 91 \\
\hline 8 & $1 \mathrm{~b}$ & $2 \mathrm{~d}$ & 70,6 & $4 \mathrm{c}$ & 94 \\
\hline 9 & $1 \mathrm{~b}$ & $2 \mathrm{e}$ & 70,6 & $4 \mathrm{e}$ & 88 \\
\hline 10 & $1 \mathrm{~b}$ & $4 \mathrm{bromomethyl} \mathrm{PhenylBA} \mathrm{(2f)}$ & 70,6 & $4 \mathrm{f}$ & 81 \\
\hline 11 & $1 \mathrm{c}$ & $2 \mathrm{~d}$ & 70,5 & $5 \mathrm{c}^{20}$ & 73 \\
\hline
\end{tabular}

Propargyl esters $\mathbf{3 a}, \mathbf{4} \mathbf{a}^{\mathbf{2 0}}$, azido esters $\mathbf{3 b}, \mathbf{4} \mathbf{c}^{\mathbf{2 1}}, \mathbf{5} \mathbf{c}^{\mathbf{2 1}}$ and borate ester $\mathbf{3 e}, \mathbf{4 e}$ and $\mathbf{4 f}$ were successfully prepared and characterized. Propargyl esters and azido esters were used in click chemistry for getting graft polymer intermediates. In a direct attempt to prepare 2d from 3- 
azido-1-propanol with phosphorous tribromide in ether gives impurities, may be azido is some affinity towards the phosphorous tribromide, but in a stepwise synthesis from 3-azido-1-propanol is feasible. Thus the 3-azido-1-propanol was converted to corresponding mesylate ${ }^{22} \mathbf{2 c}$ in quantitative yield by treated methane sulfonyl chloride in presence of base, TEA, consequently converted into iodo compound ${ }^{23} \mathbf{2 d}$ by treated with sodium iodide in acetone under reflux conditions in quantitative yields. Mesiylate $\mathbf{2 c}$ or iodo compound $\mathbf{2 d}$ can be used as reagents in the reactions.

\section{Scheme-2}

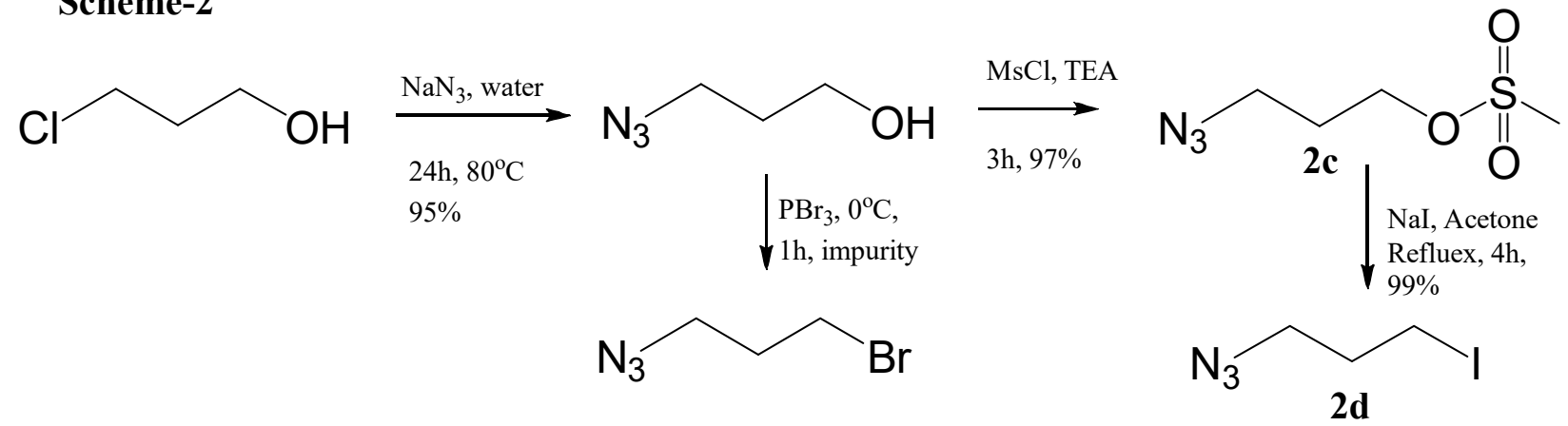

In an attempt to convert the diacid 1a to diacid chloride 6 by using thionyl chloride, isolated complex structure in quantitative yield instead of expected product. In another attempt with oxalyl chloride at temperature for 2 hours rearranged product, thioepoxide-monoacid chloride ${ }^{24} 7$ which is confirmed by single crystal x-ray. The compound 7 on reacts with one equivalent of alcohols to get corresponding mono esters 8. In Separate experiment, the diacid 1a reacts with 3azido-1-propanol in presence of EDC give the diazide product 3a in $4 \%$ whereas in newly developed DBU-DMSO method it is $20 \%$. The impurities are largely Trithiocarbonate cleaved 
thiol.

\section{Scheme-3}
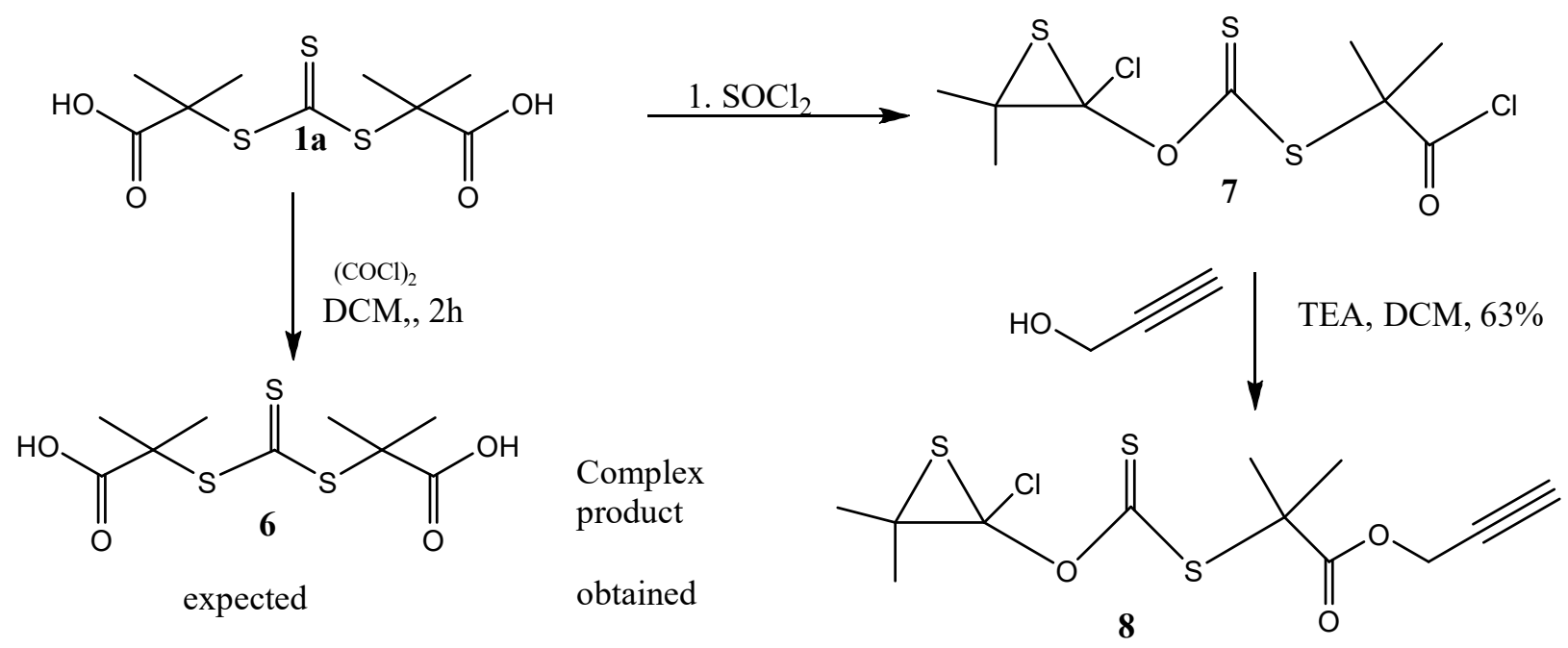

General Procedure: To a solution of acid (10 mmol, $1.0 \mathrm{eq})$ anhydrous DMSO (10 $\mathrm{mL})$ is added DBU, and substantial stirring was continued for 30 minutes at room temperature. Then the solution of halides or mesiylate $(1.0 \mathrm{eq}, 5 \mathrm{~mL})$ was then added dropwise. The reaction mixture was stirred at $65-70^{\circ} \mathrm{C}$ for given time (see table). The progress of reaction was monitored by TLC (usually 5-6h). After completion of reaction, the reaction mixture was diluted with water $(150 \mathrm{~mL})$ and extracted with dichloromethane $(75 \mathrm{~mL} \mathrm{X} \mathrm{2).} \mathrm{The} \mathrm{combined} \mathrm{organic} \mathrm{layers}$ were washed with saturated solution of sodium bicarbonate $(100 \mathrm{~mL})$, brine solution $(100 \mathrm{~mL})$, dried over anhydrous magnesium sulfate and filtered. Evaporation of the solvent followed by purification of the residue on silica gel column chromatography using a combination of ethyl acetate and hexane as eluent furnished pure ester compound, which were identified by (TLC, IR and NMR spectrum) and known samples with authentic compounds.

Conclusion, we have established a mild, simple and convenient method for synthesis of ester compounds by using DBU in anhydrous DMSO at ambient temperature. This methodology was very effective in synthesis of ester in presence of other sensitive functional groups such as 
trithiocarbonate, dithiobenzoates, nitrile, halo groups. The reaction was found to be general applicable to aliphatic and aromatic compounds. The notable advantage of this methodology is mild conditions, industrially applicable, tolerance to a wide range of functionalities. We believe this will find significant application in the field of organic synthesis.

\section{ACKNOWLEDGMENTS}

S.R.G is thankful to Prof. Brent Sumerlin, SMU for supporting in the form of post-doctoral associate fellowship during January-2006 to December-2007 and allowing to work on this project.

\section{Reference:}

1. Hawker, C. J.; Bosman, A. W.; Harth, E. Chemical Reviews 2001, 101, 3661-3688.

2. a) Matyjaszewski, K.; Xia, J. H. Chemical Reviews 2001, 101, 2921-2990.

b) Wang, J. S.;Matyjaszewski, K. J.Am. Chem.Soc. 1995, 117, 5614-5615.

3. Qiu, J.; Charleux, B.; Matyjaszewski, K. Controlled/living radical polymerization in aqueous media: Homogeneous and heterogeneous systems. Prog. Polym. Sci. 2001, 26, 2083-2134.

4. Perrier, S.; Takolpuckdee, P. Macromolecular design via reversible addition fragmentation chain transfer (RAFT)/Xanthates (MADIX) polymerization. J. Polym. Sci. A: Pol. Chem. 2005, 43, 5347-5393.

5. Barner-Kowollik, C.; Davis, T. P.; Heuts, J. P. A.; Stenzel, M. H.; Vana, P.; Whittaker, M. RAFTing down under: Tales of missing radicals, fancy architectures, and mysterious holes. J. Polym. Sci. A: Pol. Chem. 2003, 41, 365-375.

6. Moad, G.; Rizzardo, E.; Thang, S. H. Living radical polymerization by the RAFT process. Aust. J. Chem. 2005, 58, 379-410. 
7. Sumerlin, B. S.; Lowe, A. B.; Thomas, D. B.; McCormick, C. L. Aqueous solution properties of $\mathrm{pH}$-responsive $\mathrm{AB}$ diblock acrylamido copolymers synthesized via aqueous RAFT. Macromolecules, 2003, 36, 5982-5987.

8 a). Katritzky, A.R., ottometh, C., Charles, W.R.Comprehensive organic transformations, vol.5, 1996. b). Paquette, L.A. Encylopaedia of reagents for organic synthesis vol.7, 5525

9 a) Haslam, E.Tetrahedran 1980, Report No.93, 2409-2480. b). Greene, T.W.,Wuts, P.G.M, protective groups in organic synthesis, $2^{\text {nd }}$ Ed., John willy \& sons, Inc., Newyork 1991

10. a) Oediger, H.; Möller, F.; Eiter, K. Synthesis 1972, 591. b) Hermecz, I. Advances in Heterocyclic Chemistry; Katritzky, A. R., Ed.; Academic Press Inc.: New York, 1987, Chap. 42, 83. c) Product subclass 17: 1,1-Bis(nitrogen-functionalized) alk-1-enes: alk-1-ene-1,1-diamines. Kantlehner, W. Science of Synthesis, 2006, 24, 571-705. d) Product subclass 9: 1-nitrogenfunctionalized 1-(organooxy)alk-1-enes (ketene O,N-acetals). Kantlehner, W. Science of Synthesis, 2006, 24, 337-440. e) DBU (1,8-diazabicyclo[5.4.0]undec-7-ene) - a nucleophilic base. Ghosh, Nandita. Synlett, 2004, (3), 574-575. f) Synthesis of fine chemicals using DBU-promoted carbonylation reactions. $\quad$ Mizuno, Takumi. Fain Kemikaru (2003), 32(9), 512. g) Pharmaceutical materials from $\mathrm{CO} 2$. New possibility. Mizuno, Takumi. Eco Industry, 2002, 7(10), 18-27. h) DBU-the polyfunctional basic reagent. Chen, Guocai; Wang, Zhijian; Wang, Zhaoahong; Gao, Zhanxian. Huaxue Shiji, 1999, 21(6), 339-346. i) DBU - a useful chemical reagent. Wang, Naixing; Li, Jisheng. Huaxue Shiji, 1997, 19(1), 24-25, j) Applications of DBU and DBN in organic synthesis. Ni, Zhigang. Zhongguo Yiyao Gongye Zazhi, 1991, 22(4), 180-186. k) Lithium coordination by Wittig-Horner reagents formed by $\beta$ carbonyl substituted phosphonates and phosphine oxide: a review. SeydenPenne, Jacqueline. Bulletin de la Societe Chimique de France, 1988, (2), 238-242. 
11. a) Barton, D. H. R.; Zard, S. Z. J. Chem. Soc., Chem.Commun. 1985, 1098-1099. b) Barton, D. H. R.; Kervagoret, J.;Zard, S. Z. Tetrahedron 1990, 46, 7587-7597. c) Pelkey, E. T.;Chang, L.; Gribble, G. W. Chem. Commun. 1996, 1909-1910. d) Pelkey, E. T.; Gribble, G. W. Synthesis 1999, 1117-1122. e) Suzuki, M.; Yoneda, N. J. Org. Chem. 1976, 41, 1482-1487.

12. Aggarwal, V. K.; Mereu, A. Chem. Commun. 1999, 2311-2312.

13. Ballini, R.; Bosica, G.; Fiorini, D.; Petrini, M. Tetrahedron Lett. 2002, 43, 5233-5236.

14. Mizuno, T.; Ishino, Y. Tetrahedron 2002, 58, 3155-3160.

15. Mizuno, T.; Okamoto, N.; Ito, T.; Miyata, T. Tetrahedron Lett. 2000, 41, 1051-1054.

16. Shieh, W.-C.; Dell, S.; Repic, O. Org. Lett. 2001, 3, 4279-4282.

17. Shieh, W.-C.; Lozanov, M.; Loo, M.; Repic, O.; Blacklock, T. J. Tetrahedron Lett. 2003, 44, $4563-4566$.

18. Shieh, W.-C.; Dell, S.; Repic, O. J. Org. Chem. 2002, 67, 2188-2191. OR Nucleophilic Catalysis with 1,8-Diazabicyclo[5.4.0]undec-7-ene (DBU) for the Esterification of Carboxylic Acids with Dimethyl Carbonate. Wen-Chung Shieh, Steven Dell, and Oljan Repic, J. Org. Chem. 2002, 67, 2188-2191.

19 Tanaka, Shimon; Endo, Takeshi. Polymer Bulletin (Heidelberg, Germany) (2013), 70(2), 643-651.

20. Ranjan, R; Brittain, W.J. Macromolecules, 2007, 40(17), 6217-6223.

21. Gondi, S.R.; Sumerlin, B.S. Macromolecules, 2008, 40(3), 474-481.

22. Conrad, P. C.; Kwiatkowski, P. L.; Fuchs, Philip L. J.Org.Chem. 1987, 52(4), 586-591.

23. Dobrzanska, Monika Patrycja; Zawadzka, Magdalena Izabela; Radzimierski, Adam; Topolnicki, Grzegorz Witold; Cwiertnia, Grzegorz Wojciech; Mahajan, Tushar Ravindra; Fabritius, Charles-Henry; Chmielewski, Stefan; Gluza, Karolina Maria; Alvarez, Jose; et al ., PCT Int. Appl. (2019), WO 2019238786 A1 20191219.

24. Schonberg, Alexander; v. Vargha, L. Berichte der Deutschen Chemischen Gesellschaft [Abteilung] B: Abhandlungen (1931), 64B, 1390-1399. 